\title{
(6) OPEN ACCESS \\ Has the introduction of plain packaging with larger graphic health warnings changed adolescents' perceptions of cigarette packs and brands?
}

\author{
Victoria White, Tahlia Williams, Melanie Wakefield
}

\begin{abstract}
Centre for Behavioural Research in Cancer, Cancer Council Victoria, Melbourne, Victoria, Australia
\end{abstract}

\section{Correspondence to} Associate Professor Victoria White, Centre for Behavioural Research in Cancer, Cancer Council Victoria, 615 St Kilda Road, Melbourne, VIC 3004, Australia;

Vicki.white@cancervic.org.au

Received 6 October 2014 Accepted 13 January 2015

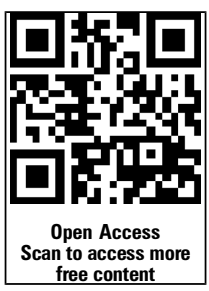

CrossMark

\section{To cite: White $V$,}

Williams T, Wakefield M.

Tob Control 2015;24:

ii42-ii49.

\begin{abstract}
Objective To examine the impact of plain packaging of cigarettes with enhanced graphic health warnings on adolescents' perceptions of pack image and perceived brand differences.

Methods Cross-sectional school-based surveys conducted in 2011 (prior to introduction of new cigarette packaging) and in 2013 (7-12 months afterwards). Students aged 12-17 years (2011 $n=6338 ; 2013$ $n=5915)$ indicated whether they had seen a cigarette pack in previous 6 months. Students rated the character of four popular cigarette brands, indicated level of agreement regarding differences between brands in ease of smoking, quitting, addictiveness, harmfulness and look of pack; and indicated positive and negative perceptions of pack image. Changes in responses of students seeing cigarette packs in the previous 6 months (2011: 60\%; 2013: 65\%) were examined.
\end{abstract}

Results Positive character ratings for each brand reduced significantly between 2011 and 2013. Changes were found for four of five statements reflecting brand differences. Significantly fewer students in 2013 than 2011 agreed that 'some brands have better looking packs than others' (2011: 43\%; 2013: 25\%, $p<0.001)$, with larger decreases found among smokers (interaction $p<0.001)$. Packs were rated less positively and more negatively in 2013 than in 2011 ( $p<0.001)$. The decrease in positive image ratings was greater among smokers.

Conclusions The introduction of standardised packaging has reduced the appeal of cigarette packs. Further research could determine if continued exposure to standardised packs creates more uncertainty or disagreement regarding brand differences in ease of smoking and quitting, perceived addictiveness and harms.

\section{INTRODUCTION}

Easily purchased and frequently displayed in public, cigarette packs are powerful communication tools. ${ }^{1-3}$ Their combined portability and visibility allows them to function as 'badge' products with the smoker taking on characteristics associated with their preferred brand. ${ }^{3}$ The tobacco industry has investigated all aspects of pack design to ensure the messages it wants communicated are understood by consumers. $^{2}$ These messages have broad reach, including to children and adolescents who have been found to describe some brands as 'exclusive', 'elegant' and 'sophisticated' while others are seen as 'common' or 'cheap'.

As part of a comprehensive approach to reducing death and disease caused by smoking, the WHOs' Framework Convention on Tobacco Control $(\text { FCTC })^{5}$ requires signatory countries to implement controls on packaging and labelling to better inform consumers about health risks (Article 11) as well as comprehensive bans on the promotion of tobacco products (Article 13). Australia, a FCTC signatory, became the first country to implement these elements of the guidelines, with all tobacco products sold in Australia from 1 December 2012 required to use the same 'drab dark brown' coloured packaging, with brand and variant names in a standard font and position on the pack. At the same time, through separate legislation, the size of the graphic health warnings (GHWs) on the front of cigarette packs and cartons increased from 30\% to $75 \%$, while remaining at $90 \%$ of the back (for legislated requirements and images of tobacco packaging in Australia preplain and postplain packaging see Scollo et $a l^{6}$ (this volume) or http://www. cancervic.org.au/plainfacts/default.asp).

Findings from experimental ${ }^{7-12}$ and qualitative studies ${ }^{4}{ }^{13}$ suggest that removing pack design elements reduces the perceived attractiveness of cigarette packs and perceived quality of cigarettes while increasing negative perceptions of smokers using those cigarette packs, among young people. Reviews have demonstrated relative consistency in these findings. ${ }^{14-16}$ Most of these studies have used mocked-up versions of plain packages designed by the researchers. No study has examined adolescents' responses to cigarette packaging after plain packaging of tobacco products has become the norm in a country. It is possible that responses found in experimental studies were influenced by the novelty of the plain packs. Additionally, given the controlled environment of experimental studies, where individuals provide an immediate response to an image shown for a standard length of time, ${ }^{7912} 17$ estimates of pack design effects on adolescents' responses from these studies may be optimal.

The specific aims of the Tobacco Plain Packaging Act are to: reduce the appeal of tobacco products; increase effectiveness of health warnings and reduce the ability of packaging to mislead consumers about the harms of smoking. ${ }^{18}$ Through the achievement of these aims and as part of a comprehensive suite of tobacco control strategies, it was intended that the legislation would contribute to efforts to reduce smoking uptake in the long term. ${ }^{18}$ Achievement of change in indictors of the legislation's specific aims in the short term would suggest that the legislation is working as intended. Studies assessing the contribution of the legislation on reduced smoking uptake would need to be conducted subsequently, using several years of postimplementation data and controlling for the effect of 
other tobacco policy (eg, tax increases, smoking bans) and tobacco industry efforts to promote smoking.

In this study, we use cross-sectional data from surveys of secondary school students conducted before (2011) and after (2013) the full implementation of the new packaging of tobacco products in Australia in December 2012, to examine whether adolescents' perceptions of cigarette packs changed. While a companion paper in this volume investigates change over time in health warning effectiveness among adolescents (the second specific aim of plain packaging), ${ }^{19}$ the current study assesses the extent to which the first and third specific aims of the Tobacco Plain Packaging Act have been achieved in the short term among adolescents who had seen a cigarette pack in the previous six months. Specifically, the study aims to determine whether there had been (1) a reduction in the perceived appeal of four of the five most popular cigarette brands; (2) a decrease in positive image, and an increase in negative image, ratings of cigarette packs and (3) decreases in the perceived differences between brands in their harmfulness, addictiveness, ease of smoking and quitting and attractiveness of their packs, 7-12 months after the introduction of the new tobacco packaging.

\section{METHODS}

\section{Study overview and design}

The current study used data from school-based surveys of adolescents conducted in two Australian states in 2011 and 2013. Both surveys had institutional ethics approval and approvals from the appropriate education authorities.

\section{School samples \\ 2011 Survey}

Data were obtained from each state's component of a national triennial survey that aimed to determine the prevalence of substance use among a representative sample of Australian students in year levels 7-12 (age 12-17 years). The procedure for the triennial survey is explained more fully elsewhere. ${ }^{20}$ In brief, within each state, schools were randomly selected from the three main Australian education sectors (government, Catholic and independent) to ensure a proportional representation of students across sectors. Principals of selected schools were approached and permission was sought to conduct the survey. If a school refused, a replacement school (the geographically closest school within the same education sector) selected at the same time as the original school was approached. In 2011, we aimed to survey students from 117 schools across two states. A total of 324 schools were approached regarding study participation and 97 agreed (30\% response rate). Schools were requested to allow one class of students from each of year levels 7-10 (average age range 1215 ) or two classes of students from each of years 11-12 (average age range 16 and 17). Researchers worked with school staff to ensure that selected classes provided a cross section of students (ie, special education classes were excluded). Data collection occurred between June and December 2011.

\section{Survey}

We aimed to survey students from the 97 secondary schools participating in the 2011 survey. Principals of schools were approached by letter and approval for participation was sought. Fifty-eight schools agreed to participate (60\%). When a school refused, a replacement school from the list of replacement schools selected for the 2011 survey was approached. Sixtythree replacement schools were approached and 24 agreed (response $38 \%$ ), giving a total of 82 schools participating in the 2013 survey. Data collection occurred between June and
November 2013. The procedure for selecting students to survey was the same as in 2011.

\section{Parental consent procedures}

In both states in 2011 and in one state in 2013, parents were informed about the study and asked to let the school know if they did not want their child to participate. Owing to requirements stipulated by the education authorities governing government and Catholic schools in the second state in 2013, an active parental consent procedure was used. In this procedure, parents were informed about the study and provided written consent to the school for the student's participation. While active parental consent procedures reduce student participation numbers and increase the statistical intraclass correlation, substance use estimates are similar to those found with passive parental consent. ${ }^{21}$

\section{Procedure for all surveys}

On an agreed day, members of the research team attended the school to administer the pencil-and-paper questionnaire to classes of students during school time. After working through a practice survey with research staff, students were given a description of the main survey and asked for study consent. Students were told they could withdraw from the survey at any time. Consenting students completed the survey independently and anonymously.

\section{Measures}

\section{Recency of seeing cigarette packs}

Students indicated how long ago they had seen a cigarette pack by choosing a response from: in the past 6 months, more than 6 months ago but less than 12 month ago, more than 12 months ago.

\section{Cigarette brand character ratings (appeal outcome)}

In both survey years, students were presented with a photographic image of each of four brands of Australian cigarettes and asked to indicate their level of agreement with three statements about the brand and the pack ('this brand appeals to me', 'the pack looks good', 'the pack looks ugly') and three statements about people who smoke the brand ('are cool', 'are successful', 'are daggy (uncool)'). These outcomes were adapted from studies assessing branded and plain packaging appeal among adolescents or young adults. ${ }^{8}{ }^{12}$ Responses were made on a five-point scale ranging from 'strongly agree' (1) to 'strongly disagree' (5) with 'not sure' in the middle (3). The brands assessed were the three most commonly smoked by Australian adolescents (Winfield (used by $44 \%$ of adolescent smokers); Peter Jackson (25\%); Longbeach (10\%) and a premium brand (Benson \& Hedges) that was smoked by $8 \%$ of adolescent smokers making it the fifth most commonly smoked brand in 2011). ${ }^{22}$ All images included a GHW as mandated at that time, with the same health warning used for each pack image within a survey year (eg, 'Smoking causes mouth and throat cancer' in 2011; 'Smoking causes mouth cancer' in 2013). For each brand, responses for the six items were summed with items recoded where necessary such that higher scores indicated a positive view (range 6-30). (Cronbach's $\alpha$ for each brand in each year was adequate: 2011 range: $0.77-0.78 ; 2013$ range: $0.73-0.75)$.

\section{Attraction of cigarette packs (appeal outcome)}

Based on our previous research, ${ }^{23} 24$ students who had seen a cigarette pack in the previous 6 months indicated their level of agreement to four positive ('cool', 'good', 'interesting', 'exciting'), and four negative ('ugly', 'daggy (uncool)', 'gross', 
'disgusting') descriptions of cigarette packs using a five-point scale ((1) 'strongly disagree' to (5) 'strongly agree'). Students could also respond that they 'cannot comment' with these responses coded as missing. Positive and negative subscale scores were created by taking the average of the five-point ratings for the items on each scale. Both scales have good internal reliability $^{23}$ with internal reliability for the current study high (positive pack image scale: $\alpha=0.85$; negative pack image scale: $\alpha=0.78$ ).

\section{Brand differences (harm and appeal outcomes)}

Based on Hammond et al, ${ }^{10}$ we assessed the extent to which plain packaging may be associated with a reduction in perceived differences in brands in harm and harm-related outcomes, as well as one appeal outcome. Students indicated their level of agreement ('strongly disagree' (1) to 'strongly agree' (4)) to five statements reflecting that some brands of cigarettes are: 'easier to smoke than others', 'more addictive than others', 'easier to quit than others', 'have more harmful substances in them than others' and 'have better looking packs than others'. Students could also give a 'don't know' (5) response. Items were recoded into three categories: 'strongly agree/agree', 'strongly disagree/ disagree' and 'don't know'.

\section{Student variables}

\section{Smoking status}

Students indicated their lifetime history of smoking (never smoked; smoked a few puffs; smoked less than 10 cigarettes; smoke more than 10 but less than 100 cigarettes; smoked 100 or more cigarettes), whether they had smoked in the past month (yes or no) and their intention to smoke in the next 12 months (seven-point scale ranging from certain not to smoke to certain to smoke). Students' responses to these questions were used to classify them into four smoking status groups that drew on the concept of smoking susceptibility ${ }^{25}$ and stage models of smoking uptake. ${ }^{26}$ Non-susceptible never-smokers (NSNS) had never smoked a cigarette and were certain they would not smoke in the next 12 months. Susceptible never-smokers (SNS) were never-smokers, who were not certain they would not smoke in the next 12 months. Triers (Triers) had had at least a puff of a cigarette, but had not smoked in the previous 4 weeks. Past month smokers (MS) were those who had had a cigarette in the previous 4 weeks.

\section{Demographic characteristics}

Students indicated their sex and age, whether their mother and father smoked (yes or no), and indicated how many of their five closest friends smoked (none through 5). The school education sector (government, Catholic and independent) was recorded.

\section{Statistical analyses}

Analyses focus on data from students aged $12-17$ years as this is the typical age range for secondary students in Australia. To correct for any oversampling or undersampling of students within age, sex and education sector groups, data were weighted to reflect the number of male and female students in each age enrolled in each education section in each state in each survey year. ${ }^{27}$ Stata V.11.2 ${ }^{28}$ was used for all analyses. Analyses adjusted for clustering of students within schools and robust SEs were used.

Students who had seen a cigarette pack in the previous 6 months formed the sample for this paper. Generalised linear regression models tested the change in scores across survey years for brand character ratings and positive and negative pack image ratings. Multinomial logistic regression examined change in the distribution of responses for the three-level categorical variables assessing brand differences. Smoking status, age, sex, school education sector and state were included as covariates in analyses examining effect of year. When the effect of year was significant, its interaction with smoking status was fitted to determine if the effect was consistent across smoking status groups. For significant interactions, means adjusted for covariates are reported in the text. Students with missing data on variables were excluded from relevant analyses.

\section{Sensitivity testing}

The analyses described above were repeated using data only from the state where there had been no change in parental consent procedures, to examine whether this change influenced findings. We also examined whether adjusting for parental and friend smoking altered the pattern of results by repeating all analyses controlling for these variables.

\section{RESULTS}

Table 1 shows the characteristics of the entire sample, the proportion of students who had seen a cigarette pack in the previous 6 months and student's smoking status for the whole sample and for those who had seen a cigarette pack in previous 6 months. Weighting the data removed differences between years in sex, age and education sector of school. Among all students, in both survey years, most of the sample were NSNS with this proportion increasing between 2011 and $2013(\mathrm{p}<0.01)$. In both the weighted and unweighted data, a greater proportion of students reported seeing a cigarette pack in the previous 6 months in 2013 than in $2011(\mathrm{p}<0.01)$. Among students seeing a cigarette pack in the previous 6 months, there was a significant increase in the proportion of NSNS and a decrease in the proportion of Triers and past MS between 2011 and 2013 (table 1). Weighted data are reported for the rest of the paper.

\section{Brand character ratings}

Among students seeing a cigarette pack in the previous 6 months, those with some smoking experience gave more positive ratings for each brand in both 2011 and 2013 (table 2). However, mean character ratings for each brand reduced significantly between 2011 and 2013 (table 2). The reduction in mean scores was generally similar among smoking status group for the four brands (no interaction between survey year and smoking status for Winfield, Peter Jackson, Benson and Hedges, borderline significance for Longbeach $(\mathrm{p}=0.054))$.

\section{Attraction of cigarette packs}

Among students who had seen a cigarette pack in the previous 6 months, negative pack image ratings increased $(\mathrm{p}<0.001)$, while positive image ratings decreased between 2011 and 2013 $(\mathrm{p}<0.001$; table 3$)$. There was a significant interaction between year and smoking status for positive image ratings $(p=0.01)$, with adjusted mean scores indicating that the decrease was greater for MS (2011: 2.56; 2013: 2.18) than NSNS (2011: 1.44; 2013: 1.36) and SNS (2011: 1.84; 2013: 1.78).

\section{Brand differences}

Table 4 shows, for students who had seen a pack of cigarettes in the previous 6 months, the proportion agreeing, disagreeing or indicating 'don't know' to the five brand differences statements. There was a significant change in the distribution of responses for four of the five statements between 2011 and 2013. For the statement 'some cigarette brands are easier to smoke than others', there was a significant increase in the proportion responding 'don't know' $(\mathrm{p}=0.006)$ and a significant decrease 
Table 1 Characteristics of all students participating in each survey, the proportion of students seeing cigarette packs in the previous 6 months and the proportion of these students in each of the smoking status groups (unweighted and weighted data)

\begin{tabular}{|c|c|c|c|c|c|c|}
\hline & \multicolumn{2}{|c|}{ Unweighted data } & \multirow[b]{2}{*}{$\mathrm{p}$ Value } & \multicolumn{2}{|c|}{ Weighted data } & \multirow[b]{2}{*}{$\mathrm{p}$ Value } \\
\hline & 2011 & 2013 & & 2011 & 2013 & \\
\hline (Total n) & $(6338)$ & $(5915)$ & & (6338) & (5984) & \\
\hline Sex (\% males) & $46 \%$ & $50 \%$ & $<0.001$ & $49 \%$ & $51 \%$ & 0.67 \\
\hline Age (mean) & 14.6 & 14.5 & $<0.001$ & 14.4 & 14.4 & 0.99 \\
\hline \multicolumn{7}{|l|}{ Attend } \\
\hline Government school & $68 \%$ & $68 \%$ & 0.016 & $61 \%$ & $59 \%$ & 0.95 \\
\hline Catholic school & $18 \%$ & $16 \%$ & & $23 \%$ & $23 \%$ & \\
\hline Independent school & $14 \%$ & $15 \%$ & & $16 \%$ & $18 \%$ & \\
\hline \multicolumn{7}{|l|}{ Smoking status } \\
\hline NSNS & $64 \%$ & $70 \%$ & $<0.001$ & $66 \%$ & $71 \%$ & 0.009 \\
\hline SNS & $8 \%$ & $8 \%$ & 0.38 & $8 \%$ & $8 \%$ & 0.82 \\
\hline TS & $17 \%$ & $14 \%$ & $<0.001$ & $16 \%$ & $13 \%$ & 0.01 \\
\hline MS & $11 \%$ & $8 \%$ & $<0.001$ & $10 \%$ & $8 \%$ & 0.08 \\
\hline Percentage with no friends who smoke & $68 \%$ & $75 \%$ & $<0.001$ & $71 \%$ & $77 \%$ & 0.016 \\
\hline Mother smokes (\% yes) & $22 \%$ & $20 \%$ & 0.07 & $21 \%$ & $19 \%$ & 0.28 \\
\hline Father smokers (\% yes) & $27 \%$ & $26 \%$ & 0.29 & $26 \%$ & $24 \%$ & 0.27 \\
\hline Saw cigarette packs in previous 6 months & $61 \%$ & $65 \%$ & $<0.001$ & $60 \%$ & $65 \%$ & 0.004 \\
\hline Among students who had seen a cigarette pack in previous 6 months $(\mathrm{N})$ & (3838) & (3819) & & (3738) & (3856) & \\
\hline \multicolumn{7}{|l|}{ Smoking status } \\
\hline NSNS & $56 \%$ & $64 \%$ & $<0.001$ & $58 \%$ & $66 \%$ & $<0.001$ \\
\hline SNS & $9 \%$ & $9 \%$ & 0.48 & $9 \%$ & $9 \%$ & 0.87 \\
\hline TS & $21 \%$ & $16 \%$ & $<0.001$ & $20 \%$ & $15 \%$ & 0.003 \\
\hline MS & $14 \%$ & $10 \%$ & $<0.001$ & $13 \%$ & $9 \%$ & 0.01 \\
\hline
\end{tabular}

MS, past month smoker; NSNS, non-susceptible never-smoker; SNS, susceptible never-smoker; TS, tried smoking.

in the proportion 'disagreeing' $(\mathrm{p}<0.001)$. For the statement 'some brands are more addictive than others', there was a decrease in the proportion disagreeing $(p=0.02)$. For the statement 'some cigarette brands contain more harmful substances than others', there was a significant decrease in the proportion of students disagreeing between 2011 and 2013

Table 2 Unadjusted mean scores (SEs) on brand character ratings for students who had seen a cigarette pack in the previous 6 months in 2011 and 2013 by smoking status (weighted data)

\begin{tabular}{|c|c|c|c|c|c|c|c|c|}
\hline & \multicolumn{4}{|c|}{ Smoking status } & \multirow[b]{2}{*}{ Total } & \multicolumn{3}{|c|}{ F-statistics and $p$ values* } \\
\hline & NSNS & SNS & Triers & MS & & Year & Smoking status & $\begin{array}{l}\text { Interaction: year } \\
\text { and smoking status }\end{array}$ \\
\hline 2011 weighted n & 2150 & 349 & 757 & 482 & 3738 & & & \\
\hline \multirow[t]{2}{*}{2013 weighted n } & 2558 & 353 & 586 & 359 & 3856 & & & \\
\hline & Mean (SE) & Mean (SE) & Mean (SE) & Mean (SE) & Mean (SE) & & & \\
\hline \multicolumn{9}{|l|}{ Winfield } \\
\hline 2011 & $9.11(0.10)$ & $10.91(0.20)$ & $11.32(0.16)$ & $15.04(0.21)$ & $10.49(0.09)$ & $F_{(1,184)}=61.09$ & $F_{(3,182)}=280.43$ & $F_{(3,182)}=1.79$ \\
\hline 2013 & $8.25(0.09)$ & $10.05(0.20)$ & $10.45(0.14)$ & $14.18(0.20)$ & $9.30(0.08)$ & $p<0.001$ & $p<0.001$ & $p=0.150$ \\
\hline \multicolumn{9}{|l|}{ Peter Jackson } \\
\hline 2011 & $9.14(0.10)$ & $11.07(0.22)$ & $11.35(0.16)$ & $15.13(0.22)$ & $10.55(0.09)$ & $F_{(1,184)}=49.59$ & $F_{(3,182)}=245.03$ & $F_{(3,183)}=1.46$ \\
\hline 2013 & $8.37(0.09)$ & $10.30(0.20)$ & $10.58(0.16)$ & $14.36(0.23)$ & $9.43(0.09)$ & $p<0.001$ & $\mathrm{p}<0.001$ & $p=0.227$ \\
\hline \multicolumn{9}{|l|}{ Longbeach } \\
\hline 2011 & $9.23(0.11)$ & $11.17(0.19)$ & $11.67(0.20)$ & $15.10(0.23)$ & $10.66(0.11)$ & $F_{(1,184)}=56.52$ & $F_{(3,182)}=238.52$ & $F_{(3,182)}=2.60$ \\
\hline 2013 & $8.31(0.09)$ & $10.25(0.18)$ & $10.75(0.17)$ & $14.17(0.23)$ & $9.39(0.08)$ & $p<0.001$ & $p<0.001$ & $p=0.054$ \\
\hline \multicolumn{9}{|l|}{ Benson \& Hedges } \\
\hline 2011 & $9.34(0.11)$ & $11.24(0.22)$ & $11.63(0.17)$ & $14.81(0.21)$ & $10.69(0.10)$ & $F_{(1,184)}=74.72$ & $F_{(3,182)}=274.25$ & $F_{(3,182)}=1.29$ \\
\hline 2013 & $8.34(0.09)$ & $10.25(0.21)$ & $10.63(0.16)$ & $13.82(0.22)$ & $9.37(0.08)$ & $p<0.001$ & $p<0.001$ & $p=0.278$ \\
\hline
\end{tabular}


Table 3 Unadjusted mean scores (SEs) on positive and negative pack image ratings for 2011 and 2013 students by smoking status for students who have seen a pack in previous 6 months (weighted data)

\begin{tabular}{|c|c|c|c|c|c|c|c|c|}
\hline & \multicolumn{4}{|l|}{ Year } & \multirow[b]{2}{*}{$\begin{array}{l}\text { Total } \\
\text { Mean (SE) }\end{array}$} & \multicolumn{3}{|c|}{ F-statistics and $p$ values* } \\
\hline & $\begin{array}{l}\text { NSNS } \\
\text { Mean (SE) }\end{array}$ & $\begin{array}{l}\text { SNS } \\
\text { Mean (SE) }\end{array}$ & $\begin{array}{l}\text { Triers } \\
\text { Mean (SE) }\end{array}$ & $\begin{array}{l}\text { MS } \\
\text { Mean (SE) }\end{array}$ & & Year & Smoking status & $\begin{array}{l}\text { Interaction: year } \\
\text { and smoking status }\end{array}$ \\
\hline \multicolumn{9}{|c|}{ Negative imaget } \\
\hline 2011 & $4.18(0.02)$ & $3.87(0.04)$ & $3.80(0.03)$ & $3.28(0.04)$ & $3.96(0.02)$ & \multirow{2}{*}{$\begin{array}{l}F_{(1,184)}=28.80 \\
p<0.001\end{array}$} & \multirow{2}{*}{$\begin{array}{l}F_{(3,182)}=158.83 \\
p<0.001\end{array}$} & \multirow{2}{*}{$\begin{array}{l}\mathrm{F}_{(3,182)}=1.01 \\
\mathrm{p}=0.39\end{array}$} \\
\hline 2013 & $4.31(0.02)$ & $4.00(0.04)$ & $3.93(0.04)$ & $3.41(0.04)$ & $4.15(0.02)$ & & & \\
\hline \multicolumn{9}{|c|}{ Positive image† } \\
\hline 2011 & $1.47(0.02)$ & $1.88(0.03)$ & $1.90(0.03)$ & $2.46(0.05)$ & $1.72(0.02)$ & \multirow{2}{*}{$\begin{array}{l}F_{(1,184)}=40.26 \\
p<0.001\end{array}$} & \multirow{2}{*}{$\begin{array}{l}F_{(3,182)}=160.57 \\
p<0.001\end{array}$} & \multirow{2}{*}{$\begin{array}{l}\mathrm{F}_{(3,182)}=3.92 \\
\mathrm{p}=0.01\end{array}$} \\
\hline 2013 & $1.34(0.02)$ & $1.75(0.04)$ & $1.77(0.03)$ & $2.33(0.05)$ & $1.52(0.02)$ & & & \\
\hline
\end{tabular}

$(\mathrm{p}<0.01)$. There was no change over time in responses to the statement 'some cigarette brands are easier to quit than others'. The largest change was found for the statement 'Some brands have better looking packs than other brands' $(\mathrm{p}<0.001)$ with fewer students agreeing with this statement in 2013 (25\%) than in 2011 (43\%).

There was a significant interaction between year and smoking status for two items: 'some cigarette brands have better looking packs than others' (interaction: $\mathrm{p}<0.001$ ) and 'some cigarette brands are more addictive than others' (interaction: $\mathrm{p}<0.003$ ). Figure 1 shows the adjusted proportions by smoking status and year for these two items. For the item 'some cigarette brands have better looking packs than others', the decrease in the proportion agreeing with this statement was greatest among those involved with smoking. For the statement 'some cigarette brands are more addictive than others', change was greatest among non-smokers, with no significant change in the responses of smokers.

Table 4 Among students who have seen cigarette pack in previous 6 months, unadjusted proportions ( $95 \%$ Cls) agreeing*, disagreeingt or who don't know for statements regarding differences in ease of smoking, ease of quitting, addictiveness, more harmful and have better looking packs between cigarette brands by year of survey (weighted data)

\begin{tabular}{|c|c|c|c|c|}
\hline \multirow[b]{2}{*}{$\begin{array}{l}\text { Some cigarette brands are: } \\
\text { (Weighted N) }\end{array}$} & \multirow{2}{*}{$\begin{array}{l}2011 \\
\%(95 \% \mathrm{Cl}) \\
(3738)\end{array}$} & \multirow{2}{*}{$\begin{array}{l}2013 \\
\%(95 \% \mathrm{CI}) \\
(3856)\end{array}$} & \multicolumn{2}{|l|}{$\chi^{2}$ statistic and $p$ value } \\
\hline & & & Year & $\begin{array}{l}\text { Interaction: year anc } \\
\text { smoking status }\end{array}$ \\
\hline \multicolumn{5}{|l|}{ Easier to smoke than others } \\
\hline Agree & $28 \%(26 \%$ to $31 \%)$ & $26 \%(23 \%$ to $28 \%)$ & $\chi_{(2)}^{2}=14.83, p<0.001$ & $\chi^{2}{ }_{(6)}=2.33, p=0.89$ \\
\hline Disagree & $22 \%(20 \%$ to $24 \%)$ & $19 \%(17 \%$ to $20 \%)$ & & \\
\hline Don't know & $49 \%(47 \%$ to $52 \%)$ & $56 \%(53 \%$ to $59 \%)$ & & \\
\hline \multicolumn{5}{|l|}{ More addictive than others } \\
\hline Agree & $33 \%$ (32\% to $35 \%)$ & $34 \%$ (32\% to $36 \%)$ & $\chi^{2}{ }_{(2)}=6.68, p=0.04$ & $\chi^{2}{ }_{(6)}=19.66, p=0.003$ \\
\hline Disagree & $20 \%(19 \%$ to $22 \%)$ & $18 \%(16 \%$ to $19 \%)$ & & \\
\hline Don't know & $46 \%(44 \%$ to $49 \%)$ & $49 \%(46 \%$ to $51 \%)$ & & \\
\hline \multicolumn{5}{|l|}{ Easier to quit than others } \\
\hline Agree & $18 \%(16 \%$ to $19 \%)$ & $16 \%(14 \%$ to $17 \%)$ & $\chi_{(2)}^{2}=1.47, p=0.48$ & NA \\
\hline Disagree & $32 \%(30 \%$ to $34 \%)$ & $31 \%(29 \%$ to $33 \%)$ & & \\
\hline Don't know & $51 \%(48 \%$ to $53 \%)$ & $54 \%(51 \%$ to $56 \%)$ & & \\
\hline \multicolumn{5}{|l|}{ Contain more harmful substances } \\
\hline Agree & $37 \%$ (35\% to $39 \%)$ & $38 \%$ ( $36 \%$ to $41 \%)$ & $\chi_{(2)}^{2}=10.63, p=0.005$ & $\chi^{2}{ }_{(6)}=6.64, p=0.36$ \\
\hline Disagree & $20 \%(18 \%$ to $22 \%)$ & $17 \%(15 \%$ to $18 \%)$ & & \\
\hline Don't know & $43 \%(41 \%$ to $45 \%)$ & $45 \%(43 \%$ to $47 \%)$ & & \\
\hline \multicolumn{5}{|c|}{ Have better looking packs than others } \\
\hline Agree & $43 \%(40 \%$ to $44 \%)$ & $25 \%(23 \%$ to $28 \%)$ & $\chi^{2}{ }_{(2)}=117.41, p<0.001$ & $\chi^{2}{ }_{(6)}=28.51, p<0.001$ \\
\hline Disagree & $25 \%$ (24\% to $27 \%)$ & $36 \%(34 \%$ to $38 \%)$ & & \\
\hline Don't know & $32 \%(30 \%$ to $35 \%)$ & $39 \%(36 \%$ to $41 \%)$ & & \\
\hline
\end{tabular}


Figure 1 Adjusted proportions of students agreeing, disagreeing or who 'don't know' if 'some brands are more addictive than others' (above) or 'some brands have better looking packs than others' (below) in 2011 and 2013 by smoking status (proportions adjusted for age, sex, education sector and state).
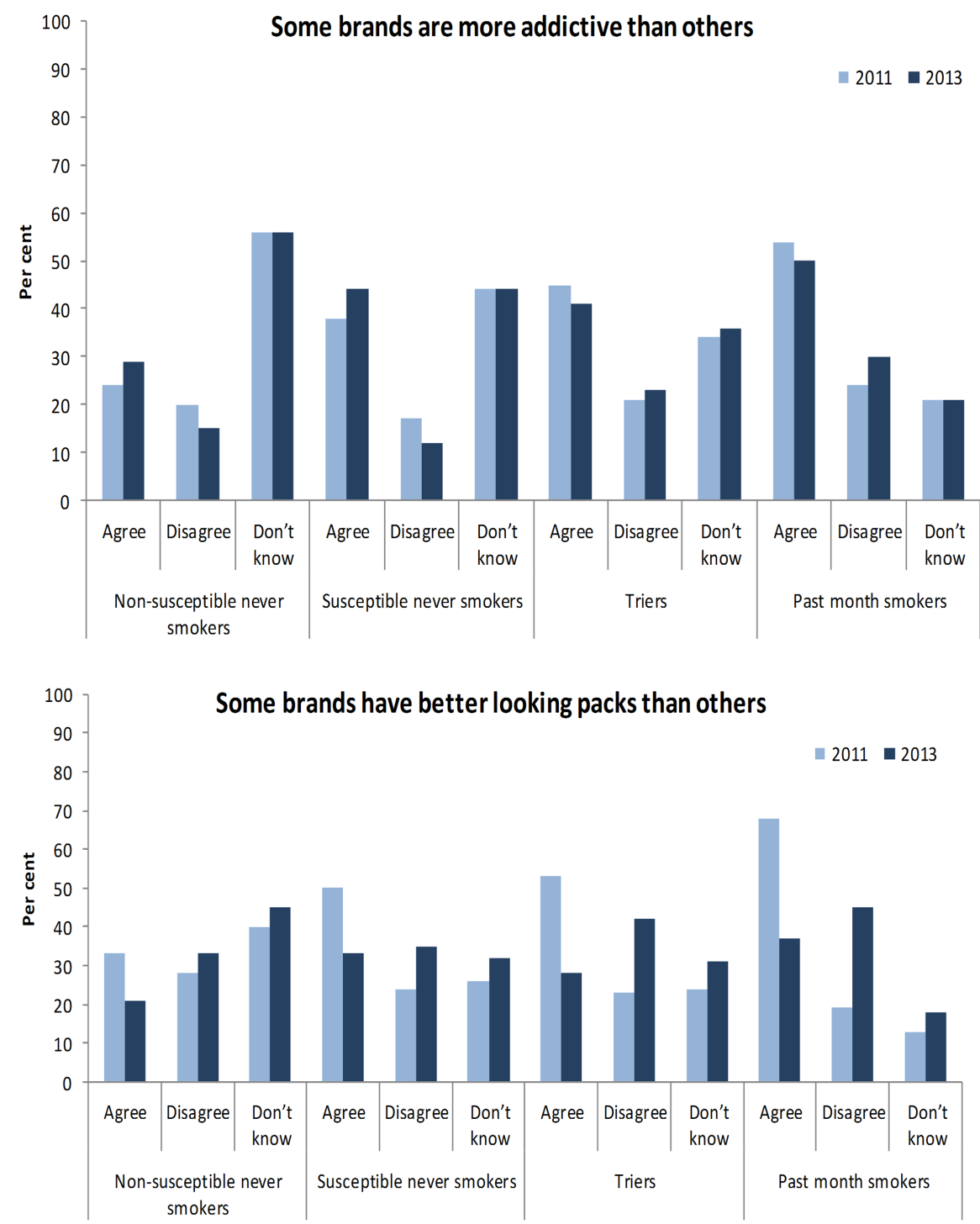

\section{Sensitivity analyses}

The pattern of results reported above was replicated in both sets of sensitivity analyses.

\section{DISCUSSION}

Ours is the first 'real-world' study to investigate the impact of standardised packaging of tobacco products on the perceptions of the image of cigarette packs and brands among adolescents. Seven to 12 months after the introduction of standardised packaging in Australia, the appeal of cigarette packs and brands to adolescents who had seen packs in the previous 6 months had decreased significantly, albeit modestly. Additionally, among students who had seen cigarette packs in the past 6 months, more were unsure as to whether brands differed in terms of their ease of being smoked in 2013 than 2011 and there was a large increase in the proportion disagreeing that some brands have better looking packs than others. The study suggests that 7-12 months after its introduction, the new controls on the cigarette packaging in Australia were starting to reduce the appeal of cigarette packs to adolescents and were beginning to reduce the pack's ability to communicate messages regarding differences in ease of smoking between brands among adolescents.

Although the reductions found in our study were relatively modest, the pattern of results are consistent with those from experimental and qualitative research showing that removing design elements from cigarette packs reduces their appeal to adolescents. ${ }^{4} 111229$ We found that among students who had seen a cigarette pack in the previous 6 months, fewer agreed that some brands have better looking packs than other brands in 2013 than in 2011. We also found reductions in positive perceptions of brand character for all four brands assessed. Encouragingly, reductions were found among all smoking status groups.

Among students who had seen a cigarette pack in the previous 6 months, there was a significant increase in negative pack image ratings between 2011 and 2013 which was consistent across smoking groups. We also found a decrease in positive pack image ratings. Although the absolute change was modest, this decrease is encouraging as our previous study found that although positive image ratings declined when GHWs covering $30 \%$ of the front of fully branded packs were introduced in 2006, they had rebounded to pre-2006 GHW levels by $2011 .^{24}$ The current study suggests that the introduction of the new cigarette packaging has again disrupted the positive image associated with cigarette packs.

One aim of plain packaging was to reduce cigarette packaging's ability to mislead consumers regarding the harmful effects of smoking. Experimental studies have shown that adolescents 
perceive cigarettes from plain packs as 'tasting cheap' compared with cigarettes from fully branded packs. ${ }^{10}$ In these studies, ratings were elicited after showing specific fully branded or plain pack images to participants. In our study, adolescents were asked whether they agreed or disagreed with a number of general statements regarding whether brands differed on a number of factors including ease of smoking, addictiveness, harmfulness and ease of quitting. Responses to these questions were mixed.

The proportion of students disagreeing with the statements 'some brands are easier to smoke than others' and 'some brands are more addictive than others' decreased, while the proportion reporting 'don't know' regarding the ease of smoking some brands increased. The pattern of results found suggests that 712 months after their introduction, the new packs were creating uncertainty regarding whether there were differences between cigarette brands' addictive qualities and their ease of being smoked. However, for the statement 'some cigarette brands contain more harmful substances than others' slightly more students agreed with this statement in 2013 than 2011. Further research is needed to determine whether, with continued exposure to the new packs, adolescents develop stronger disagreement regarding differences between brands in the harmfulness, addictiveness and ease of smoking. This is particularly important since plain packaging did not limit the use of variant names (eg, 'Distinct' or 'Fine'), which are independently associated with misperceptions of harm. ${ }^{10}{ }^{11}$ With the implementation of plain packaging in Australia, there has been greater use of longer and more evocative variant names on tobacco products. ${ }^{30}$

Several study limitations need to be noted. First, because plain packaging was introduced at the same time as the introduction of larger GHWs on the front of cigarette packs, we cannot determine whether the changes we found in adolescents' perceptions of cigarette packs are the result of plain packaging alone. For this reason, we must conclude that changes we have found are the result of the combination of the cigarette packaging changes and not just the introduction of plain packaging. Change in consent procedures in one state meant that some schools surveyed only a small number of students and this could have introduced some bias. In a study examining the impact of active parental consent on students' responses to surveys about substance use, while prevalence estimates were generally the same, there was greater similarity in the students surveyed at a particular school. ${ }^{21}$ Furthermore, sensitivity analyses suggested that the change in consent procedures in one state had minimal influence on our results.

Despite these limitations, the present study provides new information on the immediate response of adolescents to the introduction of plain packaging of cigarettes coupled with larger front of pack GHWs. Our data suggest that these changes have reduced the appeal of cigarette packs to adolescents, increased negative perceptions of packs and reduced positive perceptions regarding brand characteristics, although we note that the changes found were modest. While our data do not show that the introduction of the new cigarette packs immediately corrected adolescents' misbeliefs about differences in the ease of smoking, harmfulness and addictiveness of cigarettes from different brands, the pattern of findings does suggest that the new packs may be disrupting these beliefs and increasing uncertainty among adolescents about the effects of smoking. Future studies of adolescents' responses to the new tobacco packaging after longer exposure to the new packaging are needed to determine whether the effects we have found increase or diminish in size and whether misbeliefs about the harms of smoking are corrected. Additionally, future studies need to determine whether the new packaging has reduced smoking uptake among adolescents, as is the long-term goal of the policy.

\section{What this paper adds}

- Cigarette packs are powerful communication tools with broad reach including to children and adolescents.

- Experimental and qualitative studies suggest that packaging cigarettes in plain or standardised packs reduces perceived attractiveness of packs and perceived quality of cigarettes and corrects misperceptions about harms among adolescents. However, no study has examined adolescents' responses to plain packaging of cigarettes in a community where plain packaging is the norm.

- Seven to 12 months after the introduction of plain packaging of cigarettes with large front-of-pack graphic health warnings in Australia, this study suggests that the appeal of cigarette packs and brands to Australian adolescents had decreased significantly.

Acknowledgements The authors would like to acknowledge the work of Ms Emily Bariola who co-ordinated the national study in 2011. Dr Kerri Coomber provided advice on statistical analysis. They would like to thank and acknowledge the education authorities in participating states and the principals and contact teachers in participating schools for allowing us to conduct the survey in schools and for assisting with survey arrangements. We thank the students for participating in the surveys.

Contributors VW and MW designed study. VW analysed data and drafted manuscript. TW coordinated data collection in 2013 and oversaw data processing. TW also contributed to data analysis. The final version of the paper has been approved by all authors.

Funding Data used in this study were gathered from surveys funded fully or in part by the Australian Government Department of Health and Ageing. Cancer Councils and health departments of participating states also contributed funding for the 2011 surveys.

Competing interests The authors wish to advise that MW was a member of the Tobacco Working Group of the Australian National Preventive Health Task Force and the Expert Advisory Committee on Plain Packaging that advised the Australian Department of Health on research pertaining to the plain packaging legislation. VW holds competitive grant funding from the Victorian Cancer Agency and the National Breast Cancer Foundation, VW and MW hold such funding from the Australian National Health and Medical Research Council and MW holds such funding from the US National Institutes of Health, Australian National Preventive Health Agency and BUPA Health Foundation.

Ethics approval Both the 2011 and 2013 study had ethical approval from the lead author's institution. In both years, the survey was approved by educational authorities in both states.

Provenance and peer review Not commissioned; externally peer reviewed.

Open Access This is an Open Access article distributed in accordance with the Creative Commons Attribution Non Commercial (CC BY-NC 4.0) license, which permits others to distribute, remix, adapt, build upon this work non-commercially, and license their derivative works on different terms, provided the original work is properly cited and the use is non-commercial. See: http://creativecommons.org/ licenses/by-nc/4.0/

\section{REFERENCES}

1 Hoek J, Gendall P, Gifford H, et al. Tobacco branding, plain packaging, pictorial warnings, and symbolic consumption. Qual Health Res 2012;22:630-9.

2 Moodie C, Hastings G. Making the pack the hero, tobacco industry response to marketing restrictions in the UK: findings from a long-term audit. Int I Ment Health Addict 2011;9:24-38.

3 Wakefield M, Morley C, Horan J, et al. The cigarette pack as image: new evidence from tobacco industry documents. Tob Control 2002;11:i73-80.

4 Scheffels J, Saebo G. Perceptions of plain and branded cigarette packaging among Norwegian youth and adults: a focus group study. Nicotine Tob Res 2013;15:450-6 
5 World Health Organization. World Health Organization Framework Convention on Tobacco Control New York, United Nations World Health Organization, 2003. http:/l www.who.int.tobacco/framework/WHO_FCTC_english.pdf

6 Scollo M, Lindorff K, Coomber K, et al. Standardised packaging and new enlarged graphic health warnings for tobacco products in Australia-legislative requirements and implementation of the Tobacco Plain Packaging Act 2011 and the Competition and Consumer (Tobacco) Information Standard, 2011. Tob Control 2015;24:ii9-16.

7 White CM, Hammond D, Thrasher JF, et al. The potential impact of plain packaging of cigarette products among Brazilian young women: an experimental study. BMC Public Health 2012;12:737.

8 Moodie C, Mackintosh AM, Hastings G, et al. Young adult smokers' perceptions of plain packaging: a pilot naturalistic study. Tob Control 2011;20:367-73.

9 Lund I, Scheffels J. Young smokers and non-smokers perceptions of typical users of plain vs. branded cigarette packs: a between-subjects experimental survey. BMC Public Health 2013;13:1005.

10 Hammond D, Dockrell M, Arnott D, et al. Cigarette pack design and perceptions of risk among UK adults and youth. Eur J Public Health 2009;19:631-7.

11 Hammond D, Daniel S, White CM. The effect of cigarette branding and plain packaging on female youth in the United Kingdom. J Adolesc Health 2012;52:151-7.

12 Germain D, Wakefield MA, Durkin SJ. Adolescents' perceptions of cigarette brand image: does plain packaging make a difference? J Adolesc Health 2010;46:385-92.

13 Ford A, Moodie C, MacKintosh AM, et al. How adolescents perceive cigarette packaging and possible benefits of plain packaging. Educ Health 2013;31:83-8.

14 Stead M, Moodie C, Angus K, et al. Is consumer response to plain/standardised tobacco packaging consistent with framework convention on tobacco control guidelines? A systematic review of quantitative studies. PLOS ONE 2013;8:e75919.

15 Hammond D. Plain packaging regulations for tobacco products: the impact of standardizing the color and design of cigarette packs. Salud Pública México 2010;52:226-32

16 Hammond D. Standardized packaging of tobacco products: evidence review, 2014. http://www.tri.ie/media/3364/standardized-packaging-of-tobacco-products-evidencereview.pdf

17 Hammond D, Arnott D, Dockrell M, et al. Cigarette pack design and perceptions of risk among adults and youth. 2009 Joint Conference of SRNT and SRNT-Europe; Apr 29, 2009, Dublin, Ireland, 2009.
18 Tobacco Plain Packaging Act 2011. 2011. http://www.comlaw.gov.au/Details/ C2011A00148

19 White V, Williams T, Faulkner A, et al. Do larger graphic health warnings on standardised cigarette packs increase adolescents' cognitive processing of consumer health information and beliefs about smoking related harms? Tob Control 2015;24: ii50-7.

20 White VM, Hayman J, Hill DJ. Can population-based tobacco-control policies change smoking behaviors of adolescents from all socio-economic groups? Findings from Australia: 1987-2005. Cancer Causes Control 2008;19:631-40.

21 White VM, Hill DJ, Effendi Y. How does active parental consent influence the findings of drug-use surveys in schools? Eval Rev 2004;28:246-60.

22 White V, Bariola E. Australian secondary school students' use of tobacco, alcohol, and over-the counter and illicit substances in 2011. Melbourne, Australia: Report prepared for: Drug Strategy Branch: Australian Government Department of Health and Ageing, December 2012. http://www.nationaldrugstrategy.gov.au/internet/ drugstrategy/Publishing.nsf/content/BCBF6B2C638E1202CA257ACD0020E35C/\$File/ National\%20Report_FINAL_ASSAD_7.12.pdf

23 White $V$, Webster $B$, Wakefield M. Do graphic health warning labels have an impact on adolescents' smoking-related beliefs and behaviours? Addiction 2008;103:1562-71.

24 White V, Bariola E, Faulkner A, et al. Graphic health warnings on cigarette packs: how long before the effects on adolescents wear out? Nicotine Tob Res Published Online First: 19 Sep 2014. doi:10.1093/ntr/ntu184

25 Pierce JP, Choi WS, Gilpin EA, et al. Validation of susceptibility as a predictor of which adolescents take up smoking in the United States. Health Psychol 1996;15:355-61.

26 Mayhew KP, Flay BR, Mott JA. Stages in the development of adolescent smoking. Drug Alcohol Depend 2000;59(Suppl 1):S61-81.

27 Australian Bureau of Statistics. Schools Australia, 2014. http://www.abs.gov.au/ AUSSTATS/abs@.nsf/DetailsPage/4221.02013?OpenDocument.

28 StataCorp. Stata Statistical Software: Release 11. College Station, TX: StataCorp LP, 2009.

29 Hammond D, White C, Anderson W, et al. The perceptions of UK youth of branded and standardized, 'plain' cigarette packaging. Eur J Public Health 2014;24:537-43.

30 Scollo M, Occleston J, Bayly M, et al. Tobacco product developments coinciding with the implementation of plain packaging in Australia. Tob Control Published Online First: 30 Apr 2014. doi:10.1136/tobaccocontrol-2013-051509. 